\title{
Association between bluefin tuna schools and oceanic features in the western Mediterranean
}

\author{
F. Royer ${ }^{1,2, *}$, J. M. Fromentin ${ }^{2}$, P. Gaspar ${ }^{1}$ \\ ${ }^{1}$ Collecte Localisation Satellites, Division Océanographie Spatiale, 8-10 rue Hermès, 31526 Ramonville St. Agne, France \\ ${ }^{2}$ IFREMER, Centre de Recherche Halieutique Méditerranéen et Tropical, avenue Jean Monnet, BP 171, 34203 Sète cedex, France
}

\begin{abstract}
We present an analysis of the distribution of bluefin tuna Thunnus thynnus schools spotted during aerial surveys in the Gulf of Lions, in relation to oceanographic features. Bio-optical and thermal properties of the sea surface derived from high-resolution sensors (AVHRR and SeaWiFS) were studied on a daily basis, and an edge-detection technique was applied to detect frontal zones. Geostatistics and point-process analyses were used to evaluate the role of the environment in structuring the spatial pattern of bluefin tuna (BFT). The distribution of schools spotted was strongly nonstationary both in space and time; this is believed to be an effect of the survey design (transect sampling) and the influence of transient oceanographic structures (surface fronts and eddies). The empirical variograms indicated a spatial range of the BFT schools at around $40 \mathrm{~km}$, with substantial daily variability. Ripley's $K$ statistic, as well as autocorrelation plots, revealed that the fish schools were clustered over a wider range of scales (from 10 to $80 \mathrm{~km}$ ), indicating more spatial structure than would be expected from a random process. Finally, BFT school distributions appeared well determined by the oceanic features, except at very small scales $(<10 \mathrm{~km})$, where over-aggregation occurred, and at the largest scales of our study $(>40 \mathrm{~km})$, where over-spreading was detected. Dynamical ecological processes, such as foraging, are likely to induce this complex spatial pattern. Possible reasons for the association of tuna with fronts are presented.
\end{abstract}

KEY WORDS: Thunnus thynnus · Gulf of Lions $\cdot$ Point process analysis $\cdot$ Front detection $\cdot$ Sea surface temperature $\cdot$ Ocean colour $\cdot$ Aggregation

\section{INTRODUCTION}

The Atlantic bluefin tuna (BFT) is a large pelagic (top predator) and highly migratory fish living in temperate waters, usually from 35 to $60^{\circ} \mathrm{N}$ (Mather et al. 1995). BFT has been continually exploited in the Mediterranean Sea since ancient times (Ravier \& Fromentin 2001). However this species, which is relatively sensitive to exploitation (Fromentin \& Fonteneau 2001), is now suspected to be overfished and overexploited (Anonymous 2003), so that fishery-independent data becomes critical. Obtaining trustworthy information from scientific surveys, however, implies a better understanding of the relationship between BFT population dynamics (especially the dynamics of its spatial distribution) and main oceanic features (Fromentin 2003). The spatial association between schools of large pelagic fishes and oceanic features has already been established in the literature (e.g. Olson et al. 1994). For instance, surface fronts recently appeared to play a key role in the feeding, growth and physiology of large pelagic fishes (e.g. Dagorn et al. 2000, Lutcavage et al. 2000). However, this type of investigation remains rare because of a lack of adequate and precise data on the spatial distribution of fishes together with coincident oceanographic measurements (Laurs et al. 1984), as well as of information in the vertical dimension (remote-sensing being mainly limited to 2D; see e.g. Brill et al. 1999, 2002). Recent advances in electronic tagging and improved 3-dimensional mapping of the ocean have circumvented this last difficulty, but an in-depth analysis of the spatial distribution of BFT schools in relation to key environmental factors is still needed. 
Our purpose was to test whether BFT school distribution in the Gulf of Lions can be solely explained by key environmental variables. To do this, we compared count data of Atlantic bluefin tuna obtained by aerial surveys with sea surface temperature or ocean colour obtained by high-resolution sensors (Advanced Very High resolution Radiometer, AVHRR, and Sea-viewing Wide Field of View Sensor, SeaWiFS). Several quantitative methods (some rarely, if ever, applied in marine ecology) have been used to analyse these data. An edge-detection technique was developed to enhance frontal variability in the studied area. Estimates of the first and second moments (i.e. the mean and the variance) of the school distributions were also computed and modelled in relation to oceanic variability. A nonparametric measure, based on the point-process framework (Diggle 1983), was applied to test possible relationships between the spatial distribution of the BFT schools (e.g. point-like data) and oceanographic fields and features (considered as continuous).

\section{DATA}

Bluefin count data from aerial surveys. As part of the EU STROMBOLI project (EU-DG XIV Contract 99/022), the French Institute for the Exploitation of the Sea (IFREMER) conducted aerial surveys in the Gulf of Lions, which is a well known feeding area for juveniles (Farrugio 1981). Surveys were carried out between 2000 and 2002 in an attempt to derive an abundance index for juvenile bluefin tuna (Fromentin 2002). This technique appeared appropriate since BFT spend most of their time in the top $10 \mathrm{~m}$ of the sea (Lutcavage et al. 2000). Aerial spotting has regularly been carried out since 1993 along the Southern Australian coasts on juveniles of Southern bluefin tuna (Cowling \& O'Reilly 1999) and has been also tested on large Atlantic bluefin tuna in the West Atlantic (Lutcavage \& Kraus 1995). Flights were performed during calm days of August and September and included 2 scientists and a professional pilot. Two flight paths (covering the eastern and the western part of the gulf) were followed, each path being completed in about $5 \mathrm{~h}$. The total area covered is broadly delimited by $\left(3^{\circ} 5^{\prime} \mathrm{E}, 5^{\circ} 2^{\prime} \mathrm{E}\right)$ and $\left(42^{\circ} \mathrm{N}, 43^{\circ} 3^{\prime} \mathrm{N}\right)$. Each school spotted during a survey day, as well as each daily track, was precisely located through a GPS and a GIS (Geographical Information System)-equipped laptop (for more details on the aerial surveys see Fromentin 2002). The aerial surveys yielded a total of 80 juvenile BFT schools in 2000 from 6 flight days, 77 in 2001 from 8 flight days and 54 in 2002 from 16 flight days. Field validation was conducted using purse-seiner log-books and involved professional spotters (Fromentin 2002).
Remote-sensing data. High-resolution data sets covering the ocean's surface include measurements from various types of sensors (e.g. radiometers, scatterometers, radars). Among the most popular in fisheries oceanography are the 'Sea-Surface Temperature' (SST), and the 'Ocean Colour' (OC). SST is derived from brightness temperature using AVHRR, while OC is calculated from backscattering light level using SeaWiFS. SST and OC have been mostly used in statistical models of the ocean, as tracers of its dynamics and indices of patchiness (Mahadevan \& Campbell 2002), or within data assimilation schemes for ecosystem models (Hofmann \& Friedrichs 2001). Beyond visual inspection, their main use in fisheries oceanography is to compensate the lack of coincident physical measurement of a given fishing operation (e.g. Bigelow et al. 1999, Maury et al. 2001). Various space/time resolutions are available for these 2 sensors, from $1.1 \mathrm{~km}$ (local area coverage data, or LAC) to $4 \mathrm{~km}$ (sub-sampled global area coverage, or GAC) and $9 \mathrm{~km}$. Here we used the highest available resolution, i.e. $1.1 \mathrm{~km}$. The SeaWiFS LAC daily raw radiances were downloaded from NASA's Distributed Active Archive Center (http://eosdata.gsfc.nasa.gov/ data/dataset/SEAWIFS/). Level-2 AVHRR SST maps were supplied by the Centre de Météorologie Spatiale of Lannion (France). The ground resolution of this product is $2 \mathrm{~km}$ (Brisson et al. 2001). A total of 76 SST images (30 in 2000, 29 in 2001 and 17 in 2002) and 49 OC images (19 in 2000, 21 in 2001 and 9 in 2002) were collected to span the whole survey period. Images spoiled by clouds and nebulosity were discarded.

Data merging. All images from both sources were remapped on a Mercator grid with a common resolution of one-hundredth of a degree. Daily maps of schools spotted and remote-sensing images have been combined for illustration purposes in Figs. 1, 2 \& 4. Quantification studies were all conducted on the daily observations, since the merging process can have no ecological meaning.

\section{METHODS}

SeaWiFS data L1-L2 processing. A Level-1 to Level2 process chain was set up using SEADAS software (Fu et al. 1998). We used the OC-4 algorithm (O'Reilly et al. 1998) to derive Type a chlorophyll concentrations from the raw radiances:

$$
\begin{gathered}
\text { Chl } a\left(\mathrm{mg} \mathrm{m}^{-3}\right)=10^{\left(a 0+a 1 \cdot R+a 2 \cdot R^{2}+a 3 \cdot R^{3}\right)}+a 4, \text { with } \\
R=\log \left(\frac{\operatorname{MAX}(\operatorname{Rrs} 443, \operatorname{Rrs} 490, \operatorname{Rrs} 510)}{\operatorname{Rrs} 555}\right)
\end{gathered}
$$

with Rrs denoting raw radiance at a given wavelength. OC-4 is less accurate in coastal (Case II) than in 

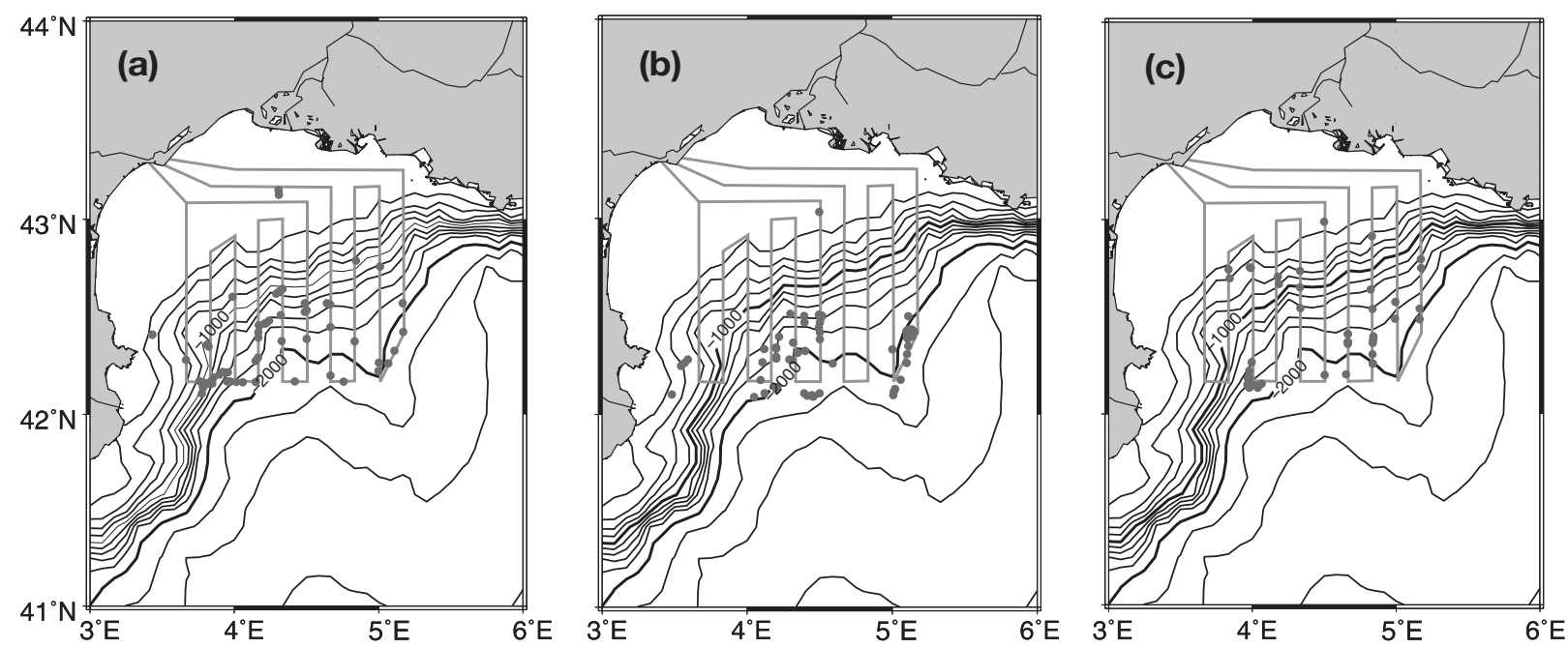

Fig. 1. Sightings of juvenile Thunnus thynnus schools in (a) 2000, (b) 2001, and (c) 2002. Bathymetry is shown by black lines, fish school locations by dots

oceanic (Case I) waters, because of high back-scattering of light due to suspended matter, and tends therefore to overestimate chlorophyll concentrations in coastal waters (Gohin et al. 2002). However, this limitation was not so critical for our purpose because (1) BFT schools are offshore (Fig. 1), and (2) we were mainly interested in image processing and front detection.

Front enhancement. An automatic front-enhancement algorithm can prove valuable in the objective assessment of the so-called 'tuna-front' association. Various edge-detection techniques are described in the literature, involving isotherm-contouring, empirical orthogonal functions (Chiswell 1994), surfacefitting (Shaw \& Vennell 2000), convolution with kernels (Simpson 1990, Canny 1986), and specifically designed algorithms (Cayula \& Cornillon 1995). Systematic analysis of AVHRR images has resulted in databases of ocean fronts (Ullman \& Cornillon 1999) and improved knowledge of frontal dynamics (Miller 2000). Nonetheless, frontal analysis of remote-sensing images remains rare in fisheries science and is mostly used in applied fisheries oceanography to support fishing activities.

We implemented the Canny-Deriche filter (Canny 1986) using the 'Interactive Data Language' (IDL). This choice was mainly because of its simplicity and its wide use in image-processing. The method basically involves 4 steps: (1) image-smoothing through convolution with a Gaussian filter, (2) gradient computation in both ( $x$ and $y$ ) directions, (3) non-maxima suppression across the edges, (4) hysteresis thresholding along the edges.

An additional step is invoked to remove fronts smaller than a given length. The parameters involved are the width of the Gaussian filter, the width of the gradient estimator, and the low/high hysteresis thresholds. Various values of these parameters were tested empirically. Daily maps of front distribution were archived and summed to produce maps of front density over the survey period (see Fig. 4).

Spatial analysis. A variety of methods used in various research fields, such as statistical mechanics in physics, oceanography, epidemiology, plant ecology or mining statistics, are now available for studying spatial processes in ecology. Detailed reviews can be found in recent methodological papers (e.g. Fortin et al. 2002). Measures of spatial structure can be roughly separated into 2 types (Dale et al. 2002): methods dealing with the spatial autocorrelation of gridded or continuous fields of data (e.g. correlograms and variograms) and methods used in the frame of point-pattern analysis (distance-based indices which consider precisely located particles or individuals; e.g. Ripley 1976). Both measures were applied in this study and are discussed.

Estimating local average: Point-process analysis comprises various tools to study the first and second moments of the spatial distribution of individuals (Diggle 1983). Its first-order property is the intensity, $\lambda(s)$ (or density surface), e.g. the mean number of events per unit area defined at Point $s$ :

$$
\lambda(s)=\lim _{d s \rightarrow 0}\left(\frac{E(Y(d s))}{d s}\right)
$$

where $E(Y(d s))$ is the expected number of individuals per area $d s$. For a stationary (homogeneous) Poisson process, $\lambda(s)$ will be constant over the study area, so $\lambda(s)=\lambda$. Classic methods for estimating the intensity usually involve quadrat counting. However such a method induces a loss of information at scales smaller than the quadrat size, 
and interpolative autocorrelation, especially for small data sets (Fortin et al. 2002). We therefore introduce kernel-smoothing, a non-parametric method to estimate the density of individuals at location $s$ :

$$
\hat{\lambda}_{b}(s)=\sum_{i=1}^{n} \frac{1}{\tau^{2}} k\left(\frac{s-s_{i}}{b}\right)
$$

where $k$ is a user-specified kernel of bandwidth $b$ and smoothing parameter $\tau$. Kernel-smoothing is an interesting way to study the spatial distribution of freeranging animals. By characterising $k$ through a Gaussian function, $\lambda(s)$ is given the following ecological meaning: it can be seen as the probability, $p$, of finding an individual near any spatial locus after a given period of time $t$, under the assumption of an unbiased random walk in an homogeneous environment (Gardiner 1983).

$$
\begin{aligned}
& p(x, y, t)=\int_{-\infty}^{\infty} p(x, y, 0) \cdot K_{D}(x, y, t) \mathrm{d} x \mathrm{~d} y, \text { where } \\
& K_{D}(x, y, t)=\frac{1}{\sqrt{2 D t} \cdot \sqrt{2 \pi}} \exp \left(-\frac{1}{2} \cdot \frac{-x^{2}-y^{2}}{2 D t}\right)
\end{aligned}
$$

$K_{D}$ is a Gaussian kernel of standard deviation $\sqrt{2 D t}$, with $D$ the diffusion coefficient and $t$ the integration time interval. In practice, this integral is computed as a convolution product in the Fourier space. The density estimate will inherit the properties of the kernel, but its choice is not as critical as the choice of the window width (Stoyan \& Stoyan 1994). The bandwidth of the Gaussian kernel is related to the diffusion coefficient $D$, which can be approximated from the average speed of a randomly-walking individual as:

$$
D=\frac{\Delta x^{2}}{2 \Delta t}
$$

where $\Delta x$ is the average displacement over time interval $\Delta t$. The resulting intensity surface can be interpreted as a potential 'search area'. Ultrasonic telemetry applied to juvenile BFT and archival tags on adult BFT provided several records of swimming speeds (Lutcavage et al. 2000, Brill et al. 2002). According to these records, the average speed is about $6 \mathrm{~km} \mathrm{~h}^{-1}$, yielding a diffusion coefficient of $18 \mathrm{~km}^{2} \mathrm{~h}^{-1}$. The standard deviation of the daily redistribution kernel used in this study is therefore set at $\sqrt{2 D t} \approx 30 \mathrm{~km}$ (with time, $t=24 \mathrm{~h})$.

Estimating spatial variance: The semivariogram (Matheron 1971) is used in geostatistics to describe how samples are related to distance. An estimate of the semivariogram is:

$$
\hat{\gamma}(h)=\frac{1}{2 N(h)} \sum_{N(h)}\left(Z\left(X_{i}\right)-Z\left(X_{j}\right)\right)^{2}
$$

where $N(h)$ is the number of pairs $Z\left(X_{i}\right)$ and $Z\left(X_{j}\right)$ separated by a distance $h$. Geostatistics are used when several sampling/recording stations cover the area of study or, as in plant ecology, when this area is subdivided in smaller objects (e.g. blocks or quadrats). The quantity of interest is then the number of individuals per unit block. In the case of animal ecology, mobile individuals (e.g. travelling between quadrats) may bias the spatial statistics. More generally, this new arrangement in the data induces interpolative autocorrelation on a scale similar to the size of each quadrat (Fortin et al. 2002). The same problem can be addressed when considering smoothed density surfaces and most types of count data.

The Lagrangian, or point-process, framework appeared more suitable for our purpose (Diggle 1983). However, linking spotting data (e.g. point-like data) to the 'oceanscape' (e.g. gridded remote-sensing fields in the present study) appears problematic since the 2 processes are essentially different. We therefore firstly compared schools spotted to delimited fronts and eddies, and then analysed location-based data (fish schools) in relation to density-based data (gridded fields). Both can be achieved in the point process framework.

The second-order property is the number of events by pairs of areas:

$$
\gamma\left(s_{i}, s_{j}\right)=\lim _{d s_{i}, d s_{j} \rightarrow 0}\left(\frac{E\left(Y\left(d s_{i}\right) Y\left(d s_{j}\right)\right)}{d s_{i} d s_{j}}\right)
$$

For a stationary Poisson process, $\gamma\left(s_{i}, s_{j}\right)=\gamma\left(s_{i}-s_{j}\right)=\gamma(d)$, i.e. $\gamma$ depends only on the direction and distance between $s_{i}$ and $s_{j}$. An equivalent of this quantity in geostatistics would be the semi-variogram. A second-order statistic in the point process is given by Ripley's $K$ function (Ripley 1976), widely used in ecology: it measures spatial structure at different ranges, under the assumption of homogeneity and isotropy. An estimate of $K$ is provided by:

$$
\hat{K}(d)=\frac{1}{\lambda} \sum_{i=1}^{n} \sum_{j=1}^{n}\left(\delta_{i j}\left(\left\|x_{i}-x_{j}\right\| \leq d\right)\right) / n
$$

where $\delta_{i j}$ is 1 if $\left\|x_{i}-x_{j}\right\| \leq d, 0$ otherwise.

An edge-effect correction is necessary near the boundaries of the study area (Ripley 1977). Under Complete Spatial Randomness (CSR), such as the Poisson process, the expected $K(d)$ is equal to $\pi \cdot d^{2}$. A variance-stabilised version of $\hat{K}$ is the Besag function (Besag 1977):

$$
\hat{L}(d)=\sqrt{\hat{K}(d) / \pi-d}
$$

$L(d)=0$ is equivalent to $K(d)=\pi \cdot d^{2}$ and indicates CSR; $L(d)>0$ indicates more clustering than expected from a Poisson process (e.g. CSR); $L(d)<0$ indicates more repulsion than expected.

Point-pattern analysis in ecology has a 1-to-1 equivalent in statistical physics, namely 'smoothed particles 
dynamics', in which similar techniques are used (e.g. pair correlation functions and kernel estimates). Another point is that classic geostatistical methods can be used on the modelled intensity surface (as well as spatial indices on the quadrat counts), but the structural (interpolative) autocorrelation induced by smoothing may severely bias the second-moment estimate.

Accounting for heterogeneity when estimating spatial variance: Spatial heterogeneity is fundamentally inherent to natural ecosystems. The assumption of homogeneity and isotropy is thus violated, and the system may be characterised by spatial autocorrelation driven by the environment (e.g. resource availability), or arising from intraspecific interactions (e.g. schooling or swarming). Therefore, spatial aggregation can arise from dependence on a patchy underlying process (for example food: plankton or nekton), without necessarily having (second-order) interaction mechanisms between individuals (the reverse is also possible). It is thus important to allow for heterogeneity when specifying an underlying model. Following Foldager \& Pedersen (2002), we modelled the spatial distribution of observed fish schools, conditional on a model taking into account process (e.g. biotic) heterogeneity, environmental variability, and possible interaction effects between fish aggregates. In practice, intensity $\lambda(x)$ is fitted to the point data as a linear combination of external variables using the method of maximum pseudolikelihood (Besag 1975). The external variables considered in this study were sea surface temperature, chlorophyll concentration, and distance to nearest thermal or ocean-colour front. Compared to the homogeneous Ripley's $K$, which assumes a Poisson random distribution, the heterogeneous version of Ripley's $K$ (Baddeley et al. 2000) assumes a user-defined intensity surface $\lambda(x)=f$ (environment) and can be written as:

$$
\hat{K}_{\text {heterog }}(d)=\sum_{i=1}^{n} \sum_{j=1}^{n} \frac{\delta_{i j}\left(\left\|x_{i}-x_{j}\right\| \leq d\right)}{\lambda\left(x_{i}\right) \lambda\left(x_{j}\right)}
$$

$K_{\text {heterog }}$ can reveal second-order aggregative properties, conditional on the environment (the CSR model is, in this case, an heterogeneous Poisson process of intensity $\lambda(x)$ ). In other words, the question we asked was 'Are the fish schools more or less aggregated than expected when linking them to environmental descriptors?'. Point-process statistics appear well suited to our purpose, compared to Generalised Linear Models (which are good at explaining models, but are likely to fail if insufficient data is available), and geostatistical methods (which are generally useful for extracting the spatial structure of objects, but are inefficient in modelling the process underlying the observed patterns). Still, the goodness-of-fit of pointpattern models is highly sensitive to the specification of the intensity surface, which requires good a priori knowledge. All statistics were implemented using the $R$ language (Ihaka \& Gentleman 1996), while point processes were analysed using the Spatstat package (Baddeley \& Turner 2002, available at: www.maths. uwa.edu.au/ adrian/spatsat.html).

\section{RESULTS}

\section{Spatial structure of BFT school patterns}

Kernel density estimates between 2000 and 2002 showed a heterogeneous distribution over the survey area: most schools were irregularly located offshore in the southern area of the survey (Fig. 2). Classic geostatistical methods were performed on the daily smoothed-density surfaces. Empirical variograms exhibited a range of around $40 \mathrm{~km}$, with roughly linear increases for shorter distances (Fig. 3). However, the variograms were highly variable from day-to-day and secondarily from year-to-year; both total variance and range varied extensively. While the variance appeared clearly related to the number of BFT schools spotted (i.e. the more detections, the greater

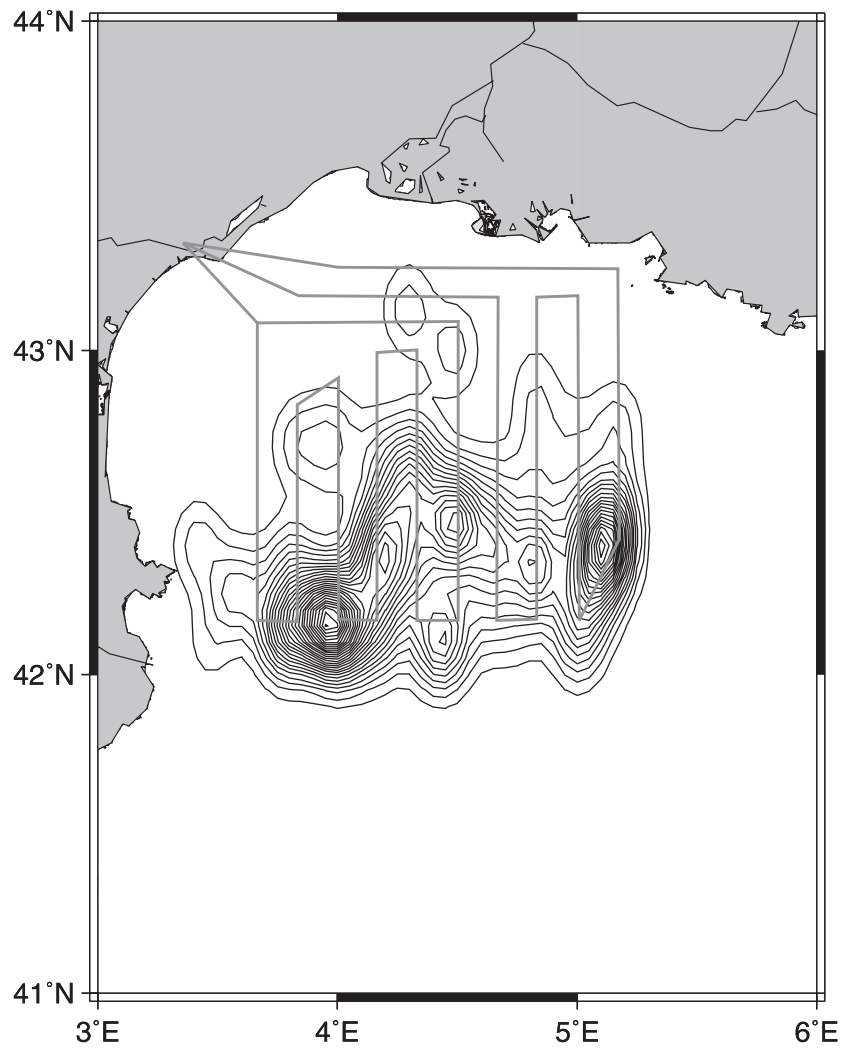

Fig. 2. Thunnus thynnus school density in the Gulf of Lions in 2000-2002, estimated with Gaussian kernel filter width of $30 \mathrm{~km}$ 

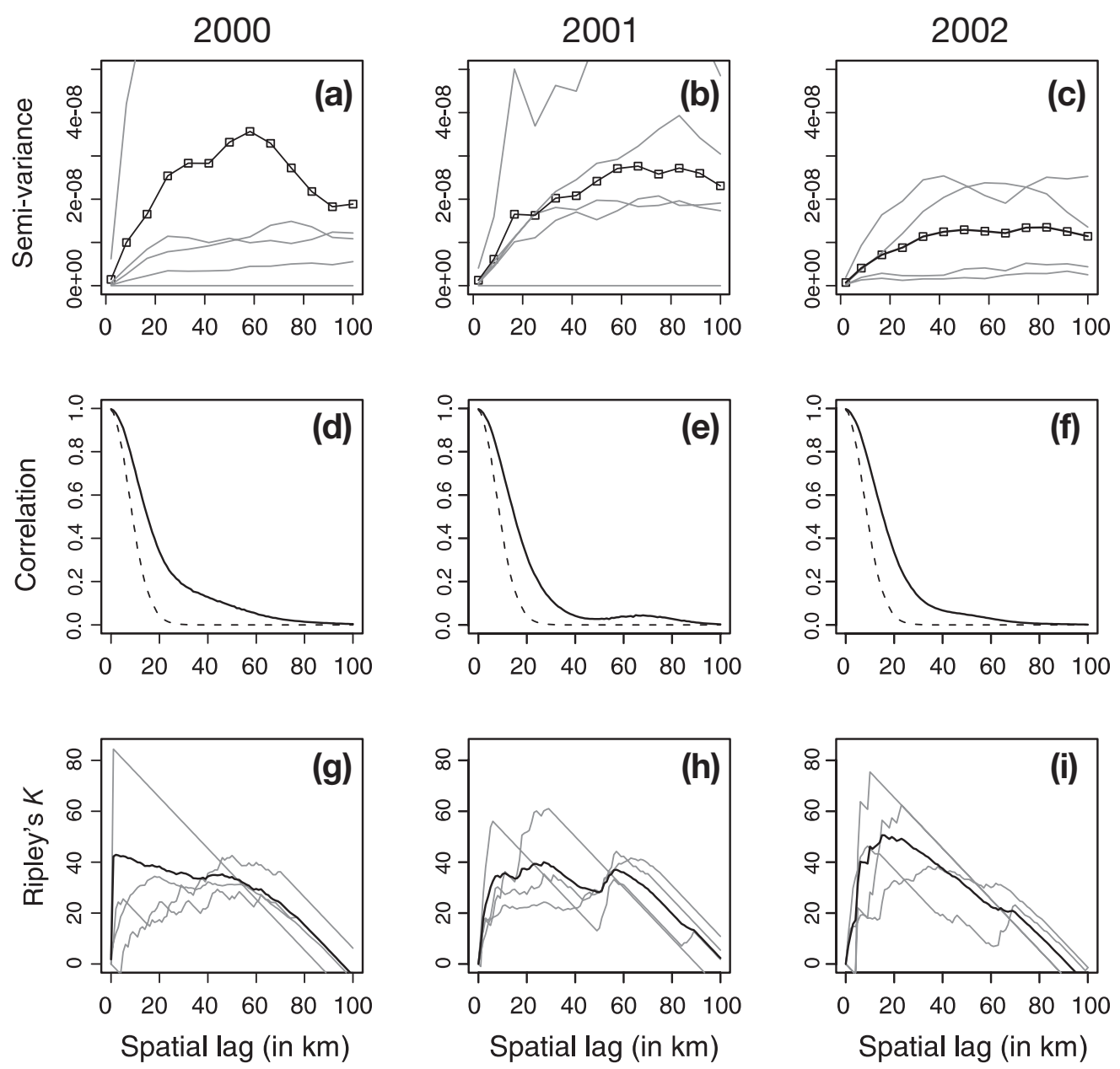

Fig. 3. Spatial statistics for Thunnus thynnus school density in 2000, 2001, and 2002. Top panels: daily empirical variograms (grey lines) with yearly-average (black line) superimposed; middle panels: spatial autocorrelation of intensity surface (black line) and spatial autocorrelation induced by kernel-smoothing (dashed line); bottom panels: corresponding Ripley $K$ functions

the variance), changes in range appeared more sensitive to the smoothing kernel bandwidth, as indicated by additional sensitivity-analysis. Spatial autocorrelation curves rapidly decreased to low values around $40 \mathrm{~km}$ (a range similar to these of the variograms), but zero values were not obtained until $80 \mathrm{~km}$ (Fig. 3). Comparison of these curves with the autocorrelation of a Gaussian signal of squared-error $D=18$ (dashed lines in Fig. 3), provided information about additional features present in the data (e.g those remaining after smoothing). The main differences between the 2 curves appeared at around $30 \mathrm{~km}$, which roughly corresponds to the bandwidth. Note that these curves were estimated by Fourier transformation of the data and were therefore smoother than the empirical variograms. Variancestabilised Ripley's $K$ were positive for all distances, which indicate aggregation/clustering in the stationary case (Fig. 3). All 3 annual curves exhibited peaks between 10 and $80 \mathrm{~km}$, indicating more aggregation than would be expected from a random Poisson process at these ranges.

A sensibility analysis was conducted using various kernel bandwidths (i.e. school swimming speeds of 3, 6 and $9 \mathrm{~km} \mathrm{~h}^{-1}$ ). As expected, the small-scale structure of BFT school patterns tended to fade when using large bandwidths, whereas low bandwidths led to high spatial variability (e.g. roughness). An average speed of $6 \mathrm{~km} \mathrm{~h}^{-1}$ appeared a satisfying trade-off for the interpretation of the correlation curves, and was furthermore sensible from a biological viewpoint.

\section{Sea-surface dynamics in the Gulf of Lions}

The frontal dynamics of the Gulf of Lions were derived from daily remote-sensing images collected during the aerial survey periods (i.e. mainly August and September 2000, 2001 and 2002; Fig. 4). The observed dynamics therefore correspond to the summer season. The mean surface temperature of the water masses in the study zone was between 21 and $22^{\circ} \mathrm{C}$. The mean chlorophyll concentration slightly exceeded $0.3 \mathrm{mg} \mathrm{m}^{-3}$, with a peak in the middle of 

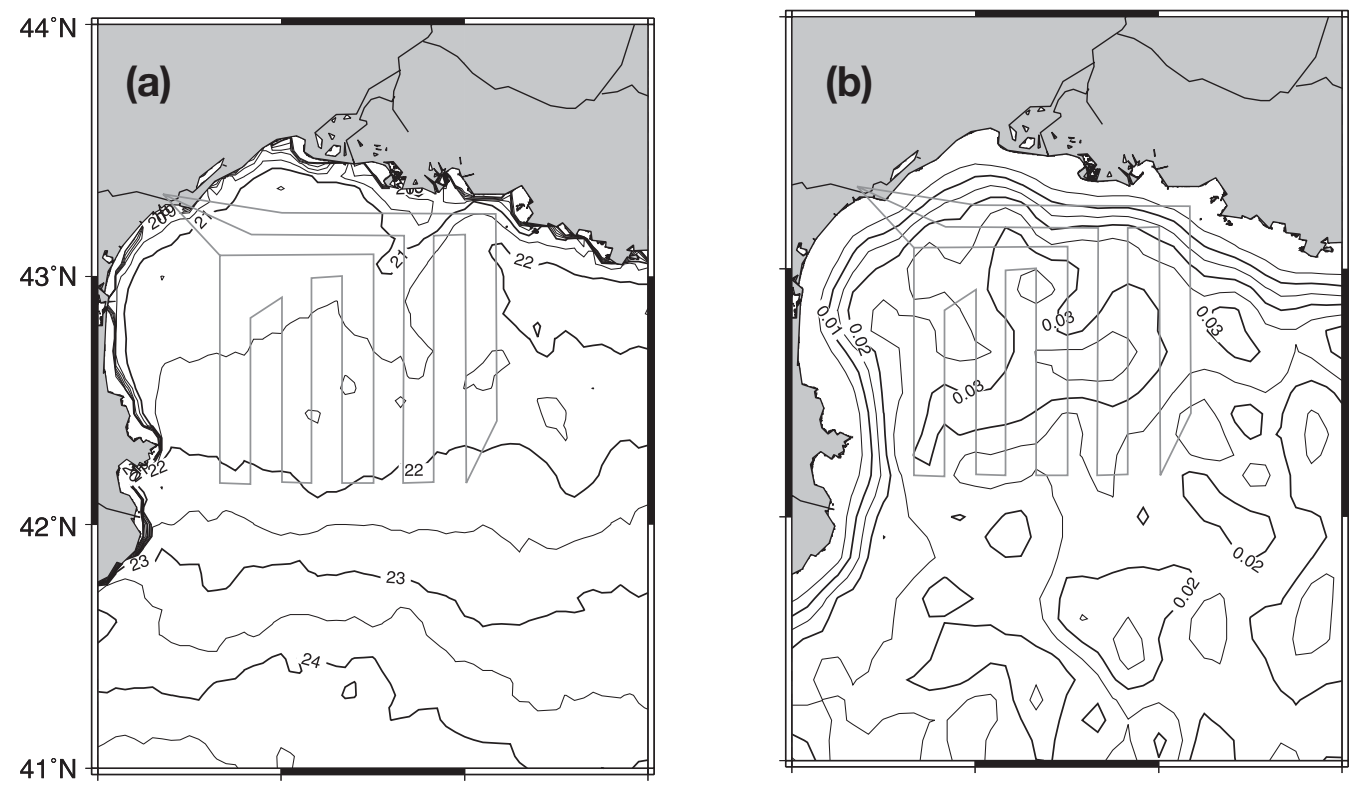

Fig. 4. (a) AVHRR sea-surface temperature $\left({ }^{\circ} \mathrm{C}\right)$, (b) SeaWiFS chlorophyll concentration $\left(\mathrm{mg} \mathrm{m}^{-1}\right)$, (c) thermal front density, and (d) ocean-colour front density $(\%)$, averaged over survey period $(2000,2001,2002)$
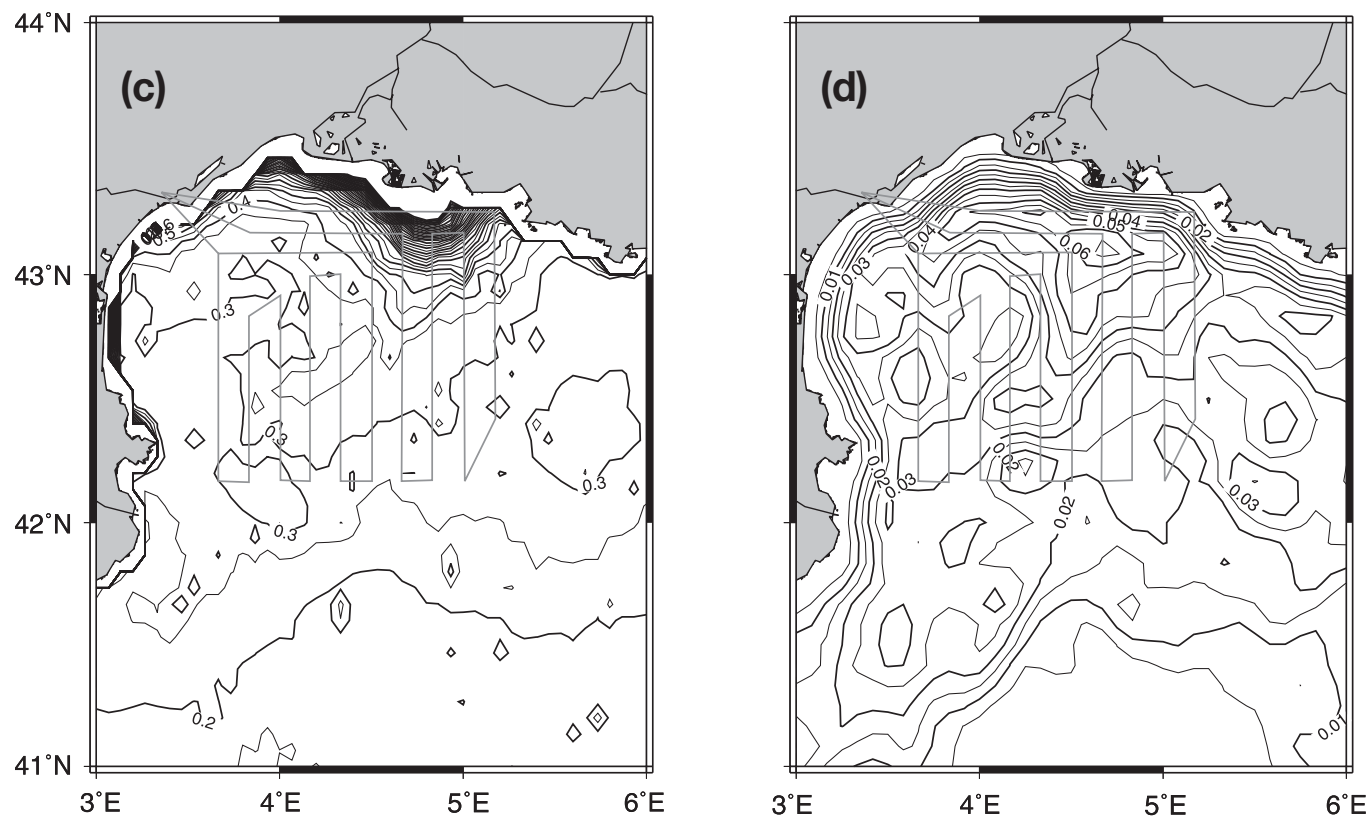

area. A strong north-south gradient was seen in surface temperature, whereas the ocean colour as well as the front density maps displayed more complex and patchy structures. The extension of the Rhône plume was well delimited in the mean chlorophyll field. In general, frontal zones are more visible on ocean-colour maps, and these were well covered by the survey path (Fig. 4). The Gulf of Lions is regularly covered by high- and low-altitude clouds, making conventional radiometers often inefficient. Cloud-free images display characteristic patterns of temperature and ocean colour delimited by fronts, jets and eddies, as seen for example in Fig. 5. This area extends from the Rhône river mouth (NE corner) to Cape Béar (SW corner), roughly following the $1000 \mathrm{~m}$ isobath. This is a clear sign of the discharge of water masses containing high concentrations of particulate and dissolved organic matter and nutrients interacting with the general dynamics of the Liguro-Provencal current. This kind of pattern is often seen when the northern wind jet (known as the mistral and tramontane) weakens, making the Rhône plume clearly visible due to its cold signature and high nutrient content. 

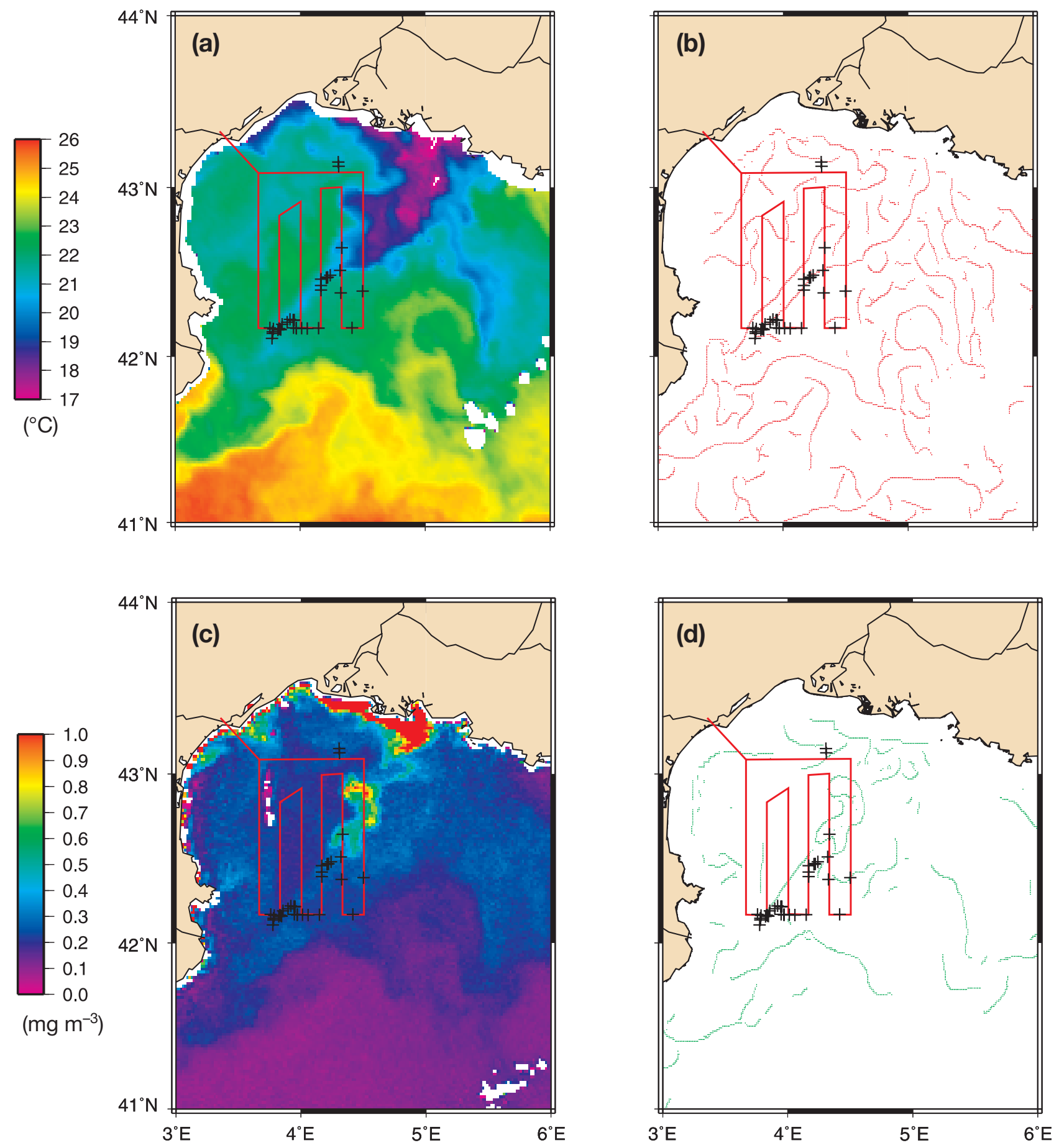

Fig. 5. Remote-sensing images on 9 September 2000 showing fish school (Thunnus thynnus) locations (+). (a) AVHRR seasurface temperature; (b) thermal fronts; (c) SeaWiFS chlorophyll a concentrations; (d) ocean-colour fronts

\section{Superimposed locations of BFT schools on environmental maps}

Plotting BFT schools spotted during 2000, 2001 and 2002 on the corresponding ocean-colour and temperature maps clearly revealed that the fish distributions were not random. Preliminary visual inspections revealed that they were generally close to surface structures such as the Rhône plume and, at a more local scale, to thermal and ocean-colour fronts. The maps corresponding to 9 September 2000 are provided as an illustrative example in Fig. 5. Few isolated schools 

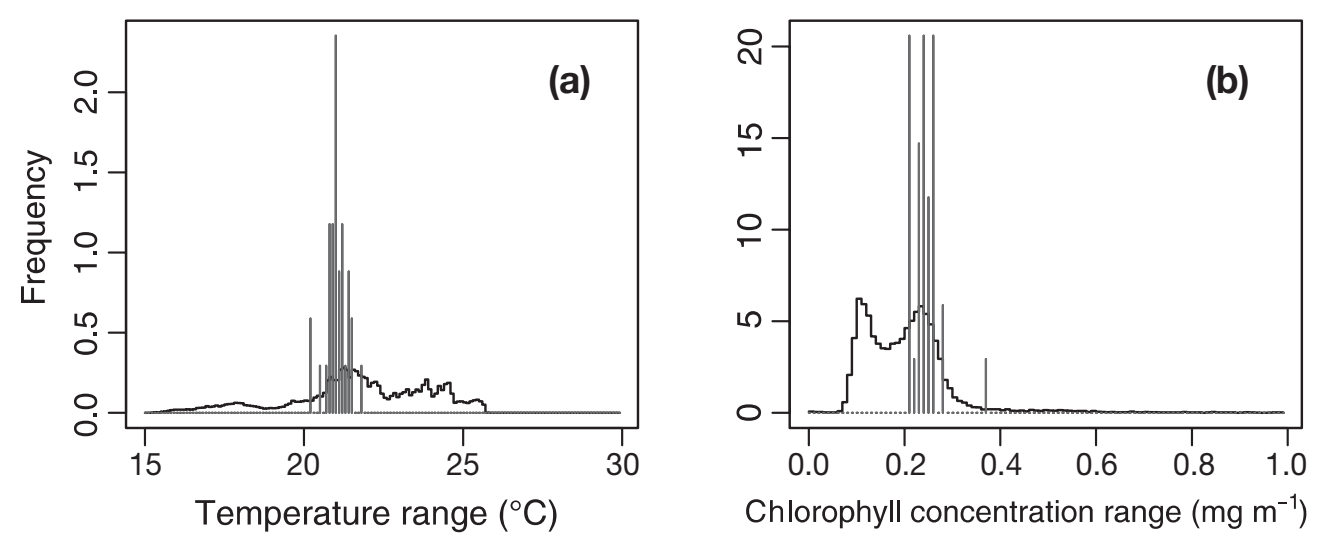

Fig. 6. Distribution of 4 environmental descriptors during survey on 9 September 2000. (a) Sea surface temperature, (b) chlorophyll concentration, (c) distance to nearest thermal front, and (d) distance to nearest oceancolour front. Continuous line: data recorded over the whole area; vertical bars: data recorded at each school location

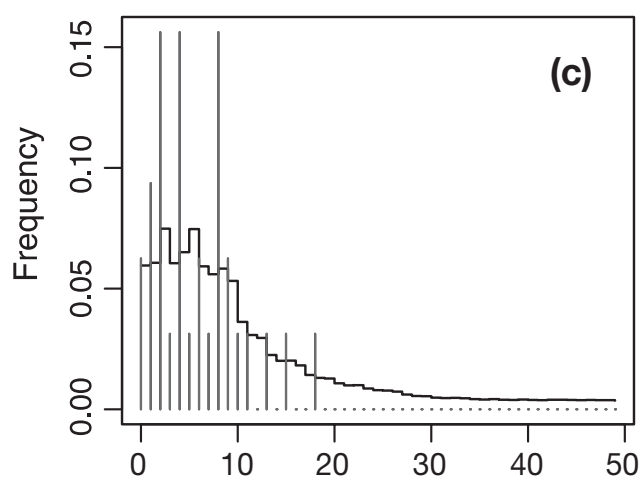

Distance to nearest thermal front $(\mathrm{km})$

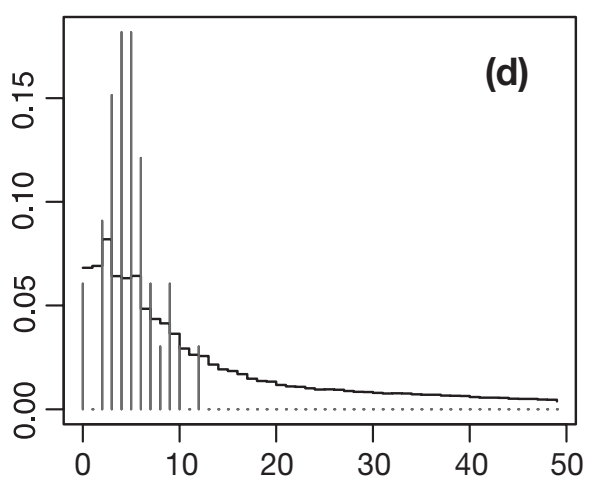

Distance to nearest ocean colour front $(\mathrm{km})$ were spotted on this specific day; most were clustered in 2 major aggregates in relatively cold, nutrient-rich waters originating from the Rhône river mouth. They also appeared closely associated with some straight thermal/ocean-colour fronts crossing the flight transects. To assess the significance of this apparent association, frequency histograms of surface-layer temperature and chlorophyll a concentrations were computed using values for that day at all BFT school locations. Histograms of distances to the nearest thermal and ocean-colour fronts were also computed, and are shown in Fig. 6. Then, the empirical distributions of these 4 variables were gathered (e.g. using values for that day at all grid points in the whole survey area). Comparison of those 2 kinds of distributions allowed us to determine if the BFT schools spotted on a specific day gathered in parallel with particular values of oceanographic variables, or if the values at each school location only reflected the oceanographic situation in the Gulf of Lions.

The BFT schools apparently occupied very narrow ranges of temperature (between 20.5 and $21.5^{\circ} \mathrm{C}$ ) and phytoplankton concentrations $\left(0.2\right.$ to $\left.0.3 \mathrm{mg} \mathrm{m}^{-3}\right)$. They also showed a preference for short distances to oceancolour fronts (between 0 and $10 \mathrm{~km}$ ) and, to a lesser extent, to thermal fronts. Kolmogorov-Smirnov 2-sample tests (Sokal \& Rohlf 1969) confirmed that the distributions of these variables were highly different from their empirical distributions in the whole area. The null hypothesis $H_{0}$ was 'BFT schools and external factors are distributed similarly'; the alternative hypothesis was 'the spatial distribution of BFT schools and explaining factors are dissimilar or weakly overlapping'. $H_{0}$ was rejected in most cases, but less strongly so for the distribution in relation to fronts $\left(\mathrm{p}=2 \times 10^{-8}\right.$ and $p=1 \times 3.10^{-9}$ for sea-surface temperature and phytoplankton concentration, respectively; $\mathrm{p}=0.05695$ and $p=0.00029$ for distances to nearest thermal front and nearest ocean-colour front, respectively). This result can be thus interpreted as follows: sea-surface temperature fields and phytoplankton fields were not randomly recorded by the BFT schools. The schools showed a preference for narrow ranges of environmental values which appeared to coincide with frontal regions. These results show that, although BFT schools may have sought precise values of surface temperature and/or phytoplankton, it is more likely that the frontal regions (that on this specific day showed strong surface variability) were better described by narrow peaks in SST or OC histograms than the strengths of the gradients themselves. 

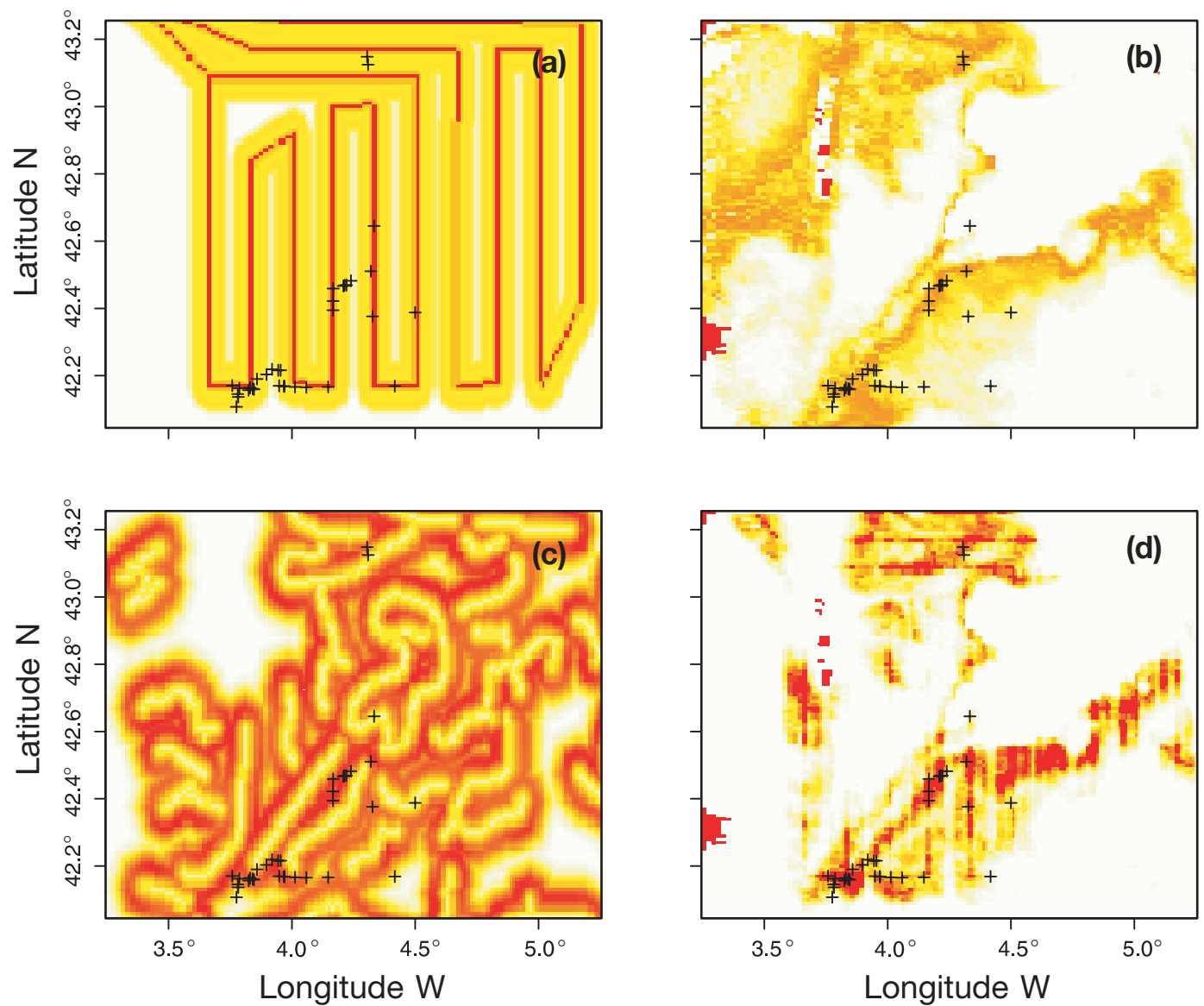

Fig. 7. Intensity surface as a function of (a) distance to plane flight-path, (b) temperature and ocean-colour field, (c) distance to nearest thermal and ocean-colour front and (d) all 5 variables (+). Fish (Thunnus thynnus) schools spotted on 9 September 2000. Distance to plane flight path calculated as perpendicular distance between fish school GPS location and on-board record of plane track

\section{BFT school distribution linked to the environment}

In an attempt to account for non-stationarity on a daily basis, the inhomogeneous versions of Ripley's $K$ were computed as a function of a linear combination of external descriptors. Data for 9 September 2000 is again shown here for illustration. We fitted 4 pointprocess models, always including the distance to the flight path as an explanatory variable (i.e. to account for patterns induced by the sampling design). The following combinations were tested: (1) a combination of the distances to the nearest ocean-colour and thermal fronts, (2) the distance to the nearest thermal front along with the surface-temperature field, (3) the distance to the nearest ocean-colour front along with the phytoplankton field, and (4) all 5 variables (Fig. 7). The intensity surfaces were fitted as third-order polynomials of these variables using the method of maximum pseudolikelihood, and the inhomogeneous Ripley's $K$ was then computed taking each fitted intensity surface as the CSR null model. The variance-stabilised $K$ is expected to be zero at all scales under the CSR hypothesis. Values above zero at a specific scale indicate over-aggregation, whereas values below zero indicate over-spreading.

The goodness of fit of the various models are illustrated by the Ripley $K$ curves in Fig. 8 . On this specific day, the model including temperature and phytoplankton performed better at short scales (e.g. less than $20 \mathrm{~km}$ ) than the models depending on distance to fronts or on distance to flight path only. Distance to flight path was an important variable in all models. As expected, the total model (gridded fields + distance to fronts + distance to flight path) performed the best and the $K$ curve displayed values close to zero from scales between 0 and $40 \mathrm{~km}$. As can be seen, the probability surface conditional on the total model is more restricted than those of the other models and the great majority of the BFT schools were distributed in the areas of highest probabilities (Fig. 7). However, the $K$ curve of the total model displayed slight positive values at around $5 \mathrm{~km}$ and became largely negative beyond $40 \mathrm{~km}$, indicating that the model could not explain some spatial structures at very small and large 

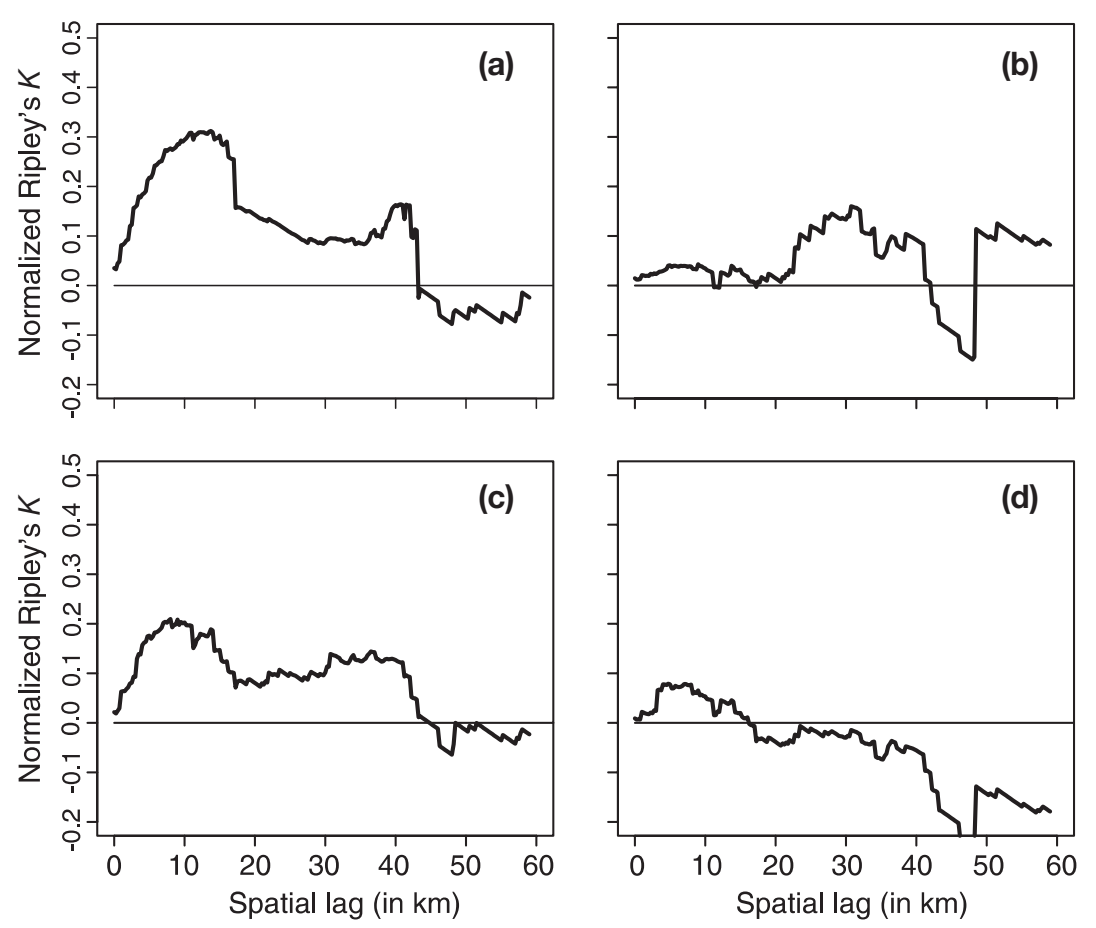

Fig. 8. Inhomogeneous Ripley $K$ statistic as a function of (a) distance to plane flight-path, (b) temperature and ocean-colour field, (c) distance to nearest thermal and ocean-colour front and (d) all 5 variables. Values above zero indicate data clustered, values below zero indicate over-spreading fronts appeared more scattered and related to other mechanisms, such as stirring and mixing with the LiguroProvencal current. Furthermore, our results showed that thermal and oceancolour fronts were decoupled in space and time, especially offshore. This is in agreement with previous findings on the patchiness of these variables. In fluid dynamics, various energy inputs from thermal and gravitational origins result in convection and advection processes leading to the formation of spatial discontinuities, where enhanced horizontal and vertical stirring occurs. Such surface heterogeneity can be seen on sea-surface temperature maps. Biological processes (e.g. reproduction, recruitment, growth) are by nature aggregative, leading to added patchiness in geophysical variables such as ocean colour. It has been shown by Mahadevan \& Campbell (2002) that the characteristic response time of phytoplankton to stirring and nutrients is different to that of temperature in response to heat fluxes. Phytoplankton may therefore be a patchy variable, with more underlying processes than temperascales. In other words, the results of the various models indicated that BFT school patterns were closely related to (or well delimited by) oceanic features, except at the smallest $(<10 \mathrm{~km})$ and largest $(>40 \mathrm{~km})$ scales, where no detection occurred in potentially favourable zones.

\section{DISCUSSION}

\section{Hydrodynamics of the Gulf of Lions}

The dynamics of the Gulf of Lions has been described in past studies using remote sensing data and in situ measurements from moored buoys and research cruises as well as numerical models (e.g. Demarcq 1985, Estournel et al. 1997). This area is under the influence of 3 dominant processes: (1) strong northern winds inducing coastal upwelling, (2) the massive discharge of nutrient-rich waters from the Rhône and (3) offshore branches of the Liguro-Provencal current. The first assessment of front occurrence in the Gulf of Lions was by Demarcq (1985), using AVHRR-derived temperature maps and CZCS (NASA Coastal Zone Color Scanner)-derived ocean-colour maps. Using new and more powerful algorithms, we have here shown that ocean-colour fronts are mostly located in the Rhône plume's extension, while thermal ture, which appears to be a more pertinent tracer of ocean circulation. In the special case of remote-sensing, Mueller \& LaViolette (1981) stated that oceancolour fronts are suggestive of turbulent diffusion, whereas thermal fronts reveal shear instabilities. Moreover, the AVHRR infrared sensor only records temperature at the very surface, whereas pigment concentration is integrated throughout the upper layer of the ocean. Thus, the position of thermal and OC fronts match only to a certain extent, both in space and time. The implications of these facts are discussed below.

\section{Spatial distribution of bluefin tuna schools}

The empirical variograms tend to indicate a spatial structure of the BFT schools at around $40 \mathrm{~km}$, but varied widely from day to day. The underlying processes (be they physical or biological) are thus likely to change over time. The second-order characteristic of a pointprocess (Ripley's $K$ ) as well as the spatial autocorrelation plots revealed that the fish schools were clustered over a wider range of scales (from 10 to $80 \mathrm{~km}$ ), indicating more aggregation than expected from a random process. As the biophysical properties of the surrounding water masses may influence the BFT schools, their spatial structure is likely to reflect this relationship. 
Superimposing the schools detected by aerial surveys on environmental maps effectively showed that their spatial distribution was linked to some specific oceanic features. This visual inspection was in agreement with the histograms and Kolmogorov-Smirnov tests, which showed that the schools were not randomly distributed in relation to sea-surface variables on a daily basis. It was also shown that, while clusters of schools were found mostly in the vicinity of frontal lines, these 'preferred' zones were better characterised in general by narrow ranges of SST and/or phytoplankton concentrations. However, we believe that this cannot be interpreted straightly as preferences: pooling the whole set of data over 2000, 2001, and 2002 yielded different results, as shown in Fig. 9. Temperature exhibited 3 peaks at 16, 21 and $24^{\circ} \mathrm{C}$ (corresponding to a seasonal signature during the different survey periods), whereas chlorophyll concentration exhibited a single peak at $0.25 \mathrm{mg} \mathrm{l}^{-1}$. It was not possible to establish any preference: the distributions of these values at each school location were not significantly different from their empirical distribution over the entire survey area. This was confirmed by the acceptance of $H_{0}$ in the Kolmogorov-Smirnov tests $(\mathrm{p}=0.102$ and $\mathrm{p}=0.303$ for SST and OC respectively). On the other hand, the distances to the nearest surface front still displayed a preference for small values (roughly less than $10 \mathrm{~km}) ; H_{0}$ was rejected for ocean colour fronts $(p=0.028)$ and, to a lesser extent, for thermal fronts $(p=0.071)$. This is interpreted as follows: when pooling the daily data, local relationships may vanish, while association with frontal features remains significant. Our conclusion is that fronts are ubiquitous features at the sea surface and may be better suited to describing relationships over entire seasons, while optima in SST or OC appear more difficult to characterise since they strongly depend on local conditions (both in space and time). Concerning front detection and characterisation, alternative techniques (e.g. dynamics-oriented, gradient-independent algorithms) may be worth investigating in fisheries oceanography, such as the method developed by Cayula \& Cornillon (1995).

BFT school distributions were in general well determined by the oceanic features (gridded fields and distance to thermal and ocean colour fronts) as soon as flight path was taken into account. We were able to roughly model the spatial distribution of BFT schools and to reproduce the situation from a simple visual superimposition of the sightings on environmental
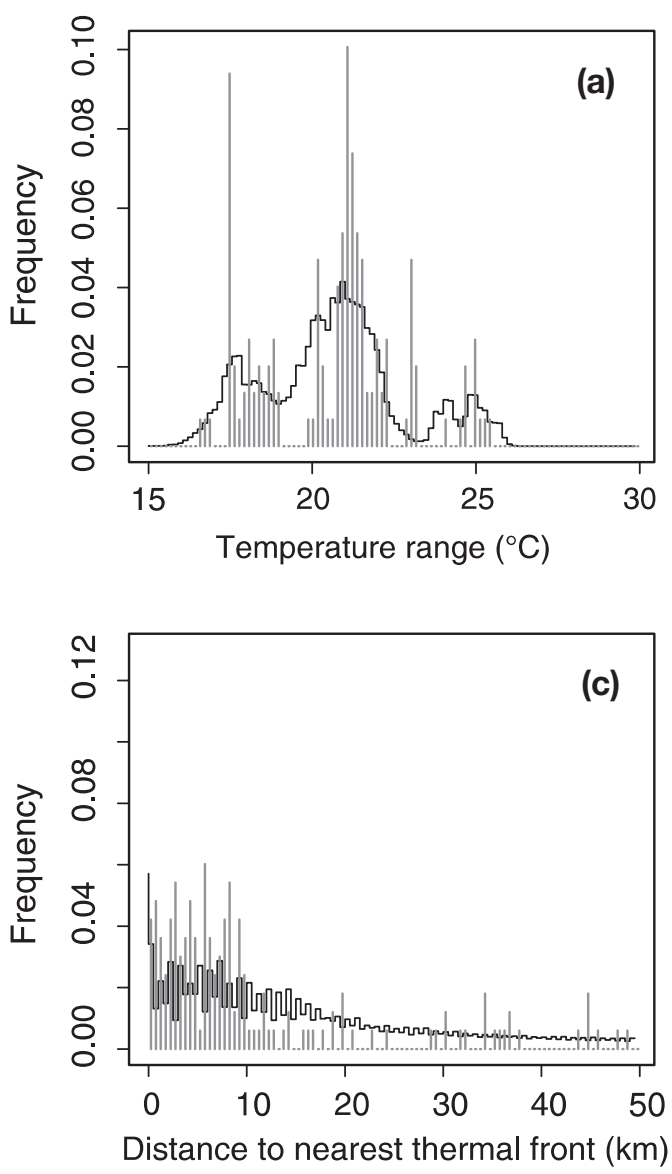
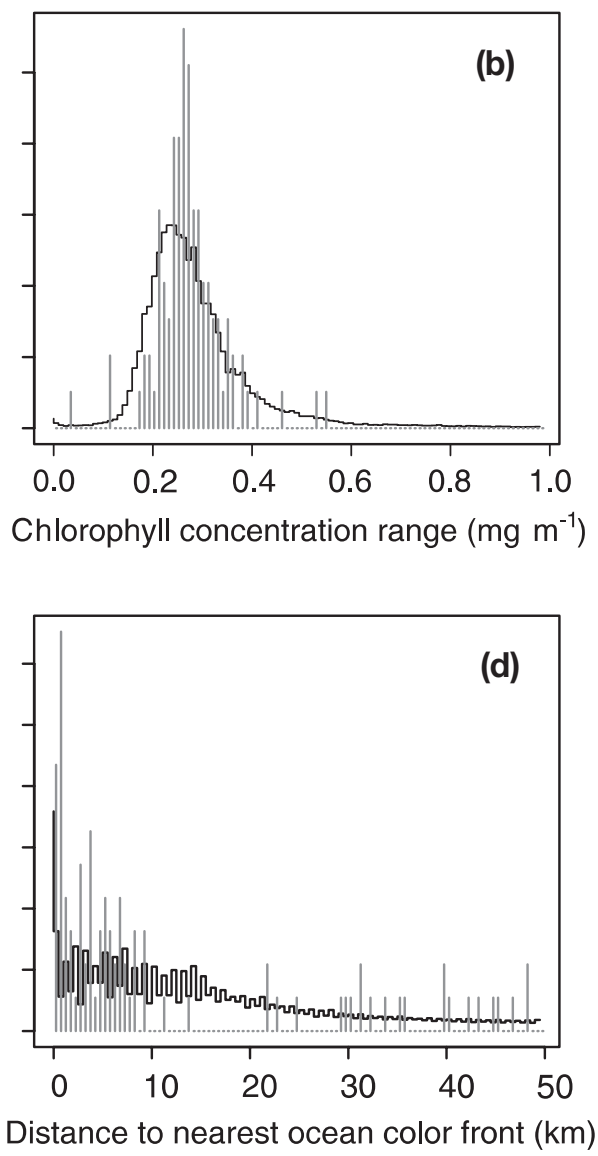

Fig. 9. Distribution of 4 environmental descriptors for the whole survey period (2000, 2001 and 2002) combined. (a) Sea surface temperature, (b) chlorophyll concentration, (c) distance to nearest thermal front, and (d) distance to nearest ocean-colour front. Continuous line: data recorded over the whole area; vertical bars: data recorded at each shool location 
maps. The spatial distribution of the BFT schools appears thus clearly non-stationary, since (1) sampling autocorrelation was induced by the survey design (i.e. the transect-sampling, although the number of sightings decreased exponentially in relation to the perpendicular distance of the flight), producing an incompletely mapped data set, and (2) BFT school distributions appeared generally linked to the ocean 'landscape', which displayed a variety of scales in its surface variability (e.g. long- and small-range gradients). This latter process in itself can induce autocorrelation and non-stationary distributions in marine species, particularly if the distribution of the schools spotted does not span the whole range of environmental variables.

However, several results also clearly pointed out that some spatial structures were still unexplained by oceanic features, especially at very small $(<10 \mathrm{~km})$ and larger $(>40 \mathrm{~km})$ scales. Such an outcome could be due to (1) environmental factors other than those examined in this study being of importance (e.g. the spatial distribution of a prey species); (2) Ripley's $K$ being biased at larger scales, since the number of comparisons decreases as lag increases (this would not, however, explain over-aggregation at small scales); (3) fast-moving fronts that are difficult to spot, as the time of the survey flight and the recording time of the images can differ by several hours; (4) some biological and/or behavioural processes that led to a departure from aggregation driven by environmental constraints. For instance, the migration patterns of juvenile BFT within the study area (i.e. the Gulf of Lions), which remain largely unknown, could explain such departure at large scales. At smaller scales, over-aggregation could also be due to interactions between BFT juvenile schools, leading to unexpectedly large schools in specific zones. Another major cause for clustering on feeding grounds may be the spatial distribution of prey, such as clupeids, that are strongly affected by oceanographic variability. Indeed, the interplay between density-independent responses to environmental features and density-dependent social behaviour is likely to produce complex patterns over a variety of scales (Steele 1989, Flierl et al. 1999).

\section{Potential benefits of association between tuna and ocean fronts}

Our results showed that surface fronts are important in partially explaining the spatial distribution of juvenile bluefin tuna schools. Ocean fronts are synoptic structures (or 'features') that form at the interface of neighbouring water masses with different oceanographic characteristics. They are associated with con- vergent flow, which results in the trapping of material in the frontal region. The advection of nutrients in conjunction with enhanced turbulence form a suitable basis for primary production (e.g. Longhurst 1998) and leads to enrichment, concentration and retention of phytoplankton and zooplankton at the fronts (e.g. Bakun 1996). Many marine fishes therefore concentrate at fronts during their early life stages (Lough \& Manning 2001). The association of top predators with coastal or permanent geostrophic fronts has also been documented by Laurs et al. (1984), Fiedler \& Bernard (1987), and Santos (1994). Inagake et al. (2001) and Lutcavage et al. (2000) described qualitatively such an association for the Pacific and the Western Atlantic bluefin, respectively. Several hypotheses were proposed to explain such association, among them the use of fronts as preferred foraging areas, the benefits of sharper temperature gradients for thermal regulation, or a loose association with trapped floating material as meeting points or navigation cues. Kirby et al.'s (2000) explicit modelling of tuna behaviour led to the conclusion that swimming and diving patterns of individuals at fronts are influenced by a diversity of external factors (ambient temperature, prey availability, etc.) driving internal factors (thermal stress, stomach fullness, etc.). Still, accurate field data is needed to finely tune and validate such explanatory models. Our results indicate that the association between juvenile BFT and frontal meanders may be linked to feeding behaviour, since tuna schools did not show striking preference for the warm or cold side of thermal fronts, while enrichment and mixing of water masses are key processes in the Gulf of Lions. Foraging in the vicinity of a phytoplankton front may be a trade-off between prey availability and hunting efficiency linked to water clarity. This is in agreement with previous findings that the relationship between tuna aggregions and frontal meanders is most probably indirect and trophicrelated, a finding confirmed by aerial spotting observations in this study (J.M.F. pers. obs.). Advected material at fronts can provide a favourable feeding environment for small clupeids, which in turn are foraged by bluefin tuna. Direct processes such as thermal regulation may be less relevant (Brill et al. 1999, Boustany et al. 2001). The identification and understanding of these indirect processes is a challenging task in explaining the small-scale behaviour of tuna.

\section{Conclusions}

In this study, we were able to provide some statistical evidence of a close association between schools of juvenile bluefin tuna and oceanic features, an association documented for this species in other areas but 
never before quantified. Point-pattern analysis and modelling offered a convenient way of linking the spatial distribution of discrete events (BFT schools) and sea-surface variability. This is of importance for future work, since the role of these oceanic features must be explicitly modelled, or at least properly parameterised, when describing the distribution of pelagic species. However, the generalisation of these results is limited by problems inherent to measurement and survey design (e.g. sensitiveness of radiometers and spotters to cloud covering), the lack of objective definition of frontal regions, and the difficulty of inferring dynamical processes from superimposed static patterns or 'snapshots'. Null models of heterogeneous spatial aggregation then become difficult to specify. We believe that, in such a Lagrangian framework, dispersion statistics can benefit from individual dynamics, and we shall conduct further work on fish behaviour, as recorded by pop-up archival tagging in the Mediterranean Sea. The ultimate goal of this approach is to provide a basis for the stochastic parameterisation of fish movements in environmentally explicit population models.

Acknowledgements. Our thanks first to H. Farrugio (IFREMER Sète) for his work on the aerial surveys and to G. Larnicol and G. Weller (CLS) for their help on spatial oceanography issues. The authors would like to thank the SeaWiFS Project (Code 970.2) and the Goddard Earth Sciences Data and Information Services Center/Distributed Active Archive Center (Code 902, Goddard Space Flight Center), for providing SeaWiFS data, as well as the Dundee University HRPT receiver for LAC data. We thank too H. Roquet and P. Le Borgne (Centre de Météorologie Spatiale of Lannion) for providing daily SST data and, for valuable help in its processing. This work could not have been conducted without the doctoral fellowship fund provided by CLS and IFREMER to F.R.

\section{LITERATURE CITED}

Anonymous (2003) Report of the 2002 Atlantic bluefin tuna stock assessment session. Col. Vol. Sci. Pap. International Commission for the Conservation of Atlantic Tuna SS(3): 710-937

Baddeley A, Moller J, Waagepetersen RP (2000) Non- and semiparametric estimation of interaction in inhomogeneous point patterns. Statistica Neerl 54:329-350

Bakun A (1996) Patterns in the ocean: ocean processes and marine population dynamics. University of California, California Sea Grant College System, San Diego, California, USA, in cooperation with Centro de Investigaciones Biológicas de Noroeste, La Paz, Baja California Sur, Mexico

Besag J (1975) Statistical analysis of non-lattice data. Statistician 24:179-195

Besag J (1977) Efficiency of pseudo-likelihood estimation for simple Gaussian fields. Biometrika 64:616-618

Bigelow KA, Boggs CH, He X (1999) Environmental effects on swordfish and blue shark catch rates in the US North Pacific longline fishery. Fish Oceanogr 8:178-198
Boustany A, Marcinek DJ, Keen J, Dewar H, Block BA (2001) Movements and temperature preferences of Atlantic bluefin tuna (Thunnus thynnus) off North Carolina: a comparison of acoustic, archival and pop-up satellite tags. In: Sibert JR, Nielsen JL (eds) Electronic tagging and tracking in marine fisheries. Kluwer, Dordrecht, p 89-108

Brill RA, Block BA, Boggs CH, Bigelow KA, Freund EV, Marcinek DJ (1999) Horizontal movements and depth distribution of large adult yellowfin tuna (Thunnus albacares) near the Hawaiian Islands, recorded using ultrasonic telemetry: implications for the physiological ecology of pelagic fishes. Mar Biol 133:395-408

Brill R, Lutcavage M, Metzger G, Bushnell P, Arendt M, Lucy J, Watson C, Foley DG (2002) Horizontal and vertical movements of juvenile bluefin tuna (Thunnus thynnus), in relation to oceanographic conditions of the western North Atlantic, determined with ultrasonic telemetry. Fish Bull Fish Wildl Serv US 100:155-167

Brisson A, Le Borgne P, Marsouin A (2001) North Atlantic regional sea surface temperature product manual, version 1.1, Météo-France, Lannion

Canny J (1986) A computational approach to edge detection. Institute of Electrical and Electronic Engineers (IEE). Transactions on pattern analysis and machine intelligence No. 8, IEEE, New York, p 679-698

Cayula JF, Cornillon P (1995) Multi-image edge detection for SST images. J Atmos Ocean Technol 12:821-829

Chiswell S (1994) Variability in sea surface temperature around New Zealand from AVHRR images. NZ J Mar Freshw Res 28:179-192

Cowling A, O'Reilly JE (1999) Background to review of aerial survey: 3rd draft 1999 Aerial Survey Workshop, Commonwealth Scientific and Industrial Research Organisation, Caloundra

Dagorn L, Menczer F, Bach. P, Olson RJ (2000) Co-evolution of movement behaviours by tropical pelagic predatory fishes in response to prey environment: a simulation model. Ecol Model 134:325-341

Dale MRT, Dixon P, Fortin MJ, Legendre P, Myers DE, Rosenberg MS (2002) Conceptual and mathematical relationships among methods for spatial analysis. Ecography 25: $558-577$

Demarcq H (1985) Applications de la télédétection infrarouge et visible en océanographie. $\mathrm{PhD}$ thesis, Université Aix-Marseille II

Diggle PJ (1983) Statistical analysis of spatial point patterns, Academic Press, London

Estournel C, Kondrachoff V, Marsaleix P, Vehil R (1997) The plume of the Rhone: numerical simulation and remote sensing. Contin Shelf Res 17:899-924

Farrugio H (1981) Exploitation et dynamique des populations de thon rouge, Thunnus thynnus (Linné 1758) AtlantoMéditerranéennes. PhD thesis, Université des Sciences et Techniques du Languedoc

Fiedler PC, Bernard HJ (1987) Tuna aggregation and feeding near fronts observed in satellite imagery. Contin Shelf Res 7:871-881

Flierl G, Grünbaum D, Levin S, Olson DB (1999) From individuals to aggregations: the interplay between behavior and physics. J Theor Biol 196:397-454

Foldager L, Pedersen J (2002) Spatial distribution of detected single fish: an application of the log Gaussian Cox process, Report No. 03, Biometry Research Unit, Department of Agricultural Systems, Danish Institute of Agricultural Sciences, Tjele

Fortin MJ, Dale MRT, Ver Hoef J (2002) Spatial analysis in ecology. In: El-Shaarawi AH, Piegorsch WW (eds) 
Encyclopedia of environmetrics, Vol 4, Wiley, Chichester, p 2051-2058

Fromentin JM (2002) Final Report of STROMBOLI. Report No. EU-DG XIV project 99/022, European Community DG XIV, Brussels

Fromentin JM (2003) The East Atlantic and Mediterranean bluefin tuna management: uncertainties and alternatives. Sci Mar 67:51-62

Fromentin JM, Fonteneau A (2001) Fishing effects and life history traits: a case-study comparing tropical versus temperate tunas. Fish Res 53:133-150

Fu G, Baith KS, McClain CR (1998) SeaDAS: the SeaWiFS data analysis system. In: Proceedings of the 4th Pacific Ocean Remote Sensing Conference, Qingdao, China, p 73-79

Gardiner CW (1983) Handbook of stochastic processes for physics, chemistry and the natural sciences, SpringerVerlag, Berlin

Gohin F, Druon JN, Lampert L (2002) A five channel chlorophyll concentration algorithm applied to SeaWiFS data processed by SeaDAS in coastal waters. Int J Remote Sens 23:1639-1661

Hofmann EE, Friedrichs MAM (2001) Models: biogeochemical data assimilation, Academic Press, London

Ihaka R, Gentleman R (1996) R: A Language for Data Analysis and Graphics. J Comput Graph Stat 5:299-314

Inagake D, Yamada H, Segawa K, Okazaki M, Nitta A, Itoh T (2001) Migration of young bluefin tuna, Thunnus orientalis, through archival tagging experiments and its relation with oceanographic conditions in the Western North Pacific. Bull Nat Res Inst Far Seas Fish 38:53-81

Kirby DS, Fiksen Ø, Hart PJB (2000) A dynamic optimization model for the behaviour of tunas at ocean fronts. Fish Oceanogr 9:328-342

Laurs RM, Fiedler PC, Montgomery DR (1984) Albacore tuna catch distribution relative to environment features observed from satellites. Deep-Sea Res 31:1085-1099

Longhurst AR (1998) Ecological geography of the sea. Academic Press, San Diego

Lough RG, Manning JP (2001) Tidal-front entrainment and retention of fish larvae on the southern flank of Georges Bank. Deep-Sea Res II 48(1-3):631-644

Lutcavage M, Kraus S (1995) The feasibility of direct photographic assessment of giant bluefin tuna, Thunnus thynnus, in New England waters. Fish Bull 93:495-503

Lutcavage M, Brill R, Skomal GB, Chase BC, Goldstein J, Tutein J (2000) Tracking adult North Atlantic bluefin tuna (Thunnus thynnus) in the northwestern Atlantic using ultrasonic telemetry. Mar Biol 137:347-358

Editorial responsibility: Otto Kinne (Editor),

Oldendorf/Luhe, Germany)
Mahadevan A, Campbell JW (2002) Biogeochemical patchiness at the sea surface. Geophys Res Lett 29:32-36

Mather FJ, Mason JM, Jones AC (1995) Historical document: life history and fisheries of Atlantic bluefin tuna. Report No. 370, National Marine Fisheries Service, Miami, FL

Maury O, Gascuel D, Marsac F, Fonteneau A, De Rosa AL (2001) Hierarchical interpretation of non-linear relationships linking yellowfin tuna (Thunnus albacares) distribution to the environment in the Atlantic Ocean. Can J Fish Aquat Sci 58:1-13

Miller P (2000) Multispectral front maps for auto-detection of ocean colour features from SeaWiFS and MODIS. In: Barale V, Gower JFR, Alberostanza L (eds) Oceans from Space, Venice 2000. Joint Research Center, Venice

Mueller JL, LaViolette PE (1981) Color and temperature signatures of ocean fronts observed with the Nimbus-7 CZCS. In: Gower JFR (ed) Oceanography from space. Plenum Press, New York, p 295-302

Olson DB, Hitchcock GL, Mariano AJ, Ashjian CJ, Peng G, Nero RW, Podestá GP (1994) Life on the edge: marine life and fronts. Oceanography 7:52-60

O'Reilly JE, Maritorena S, Mitchell BG, Siegel DA, Carder KL, Garver SA, Kahru M, McClain C (1998) Ocean color chlorophyll algorithms for SeaWiFS. J Geophys Res 103: 24937-24953

Ravier C, Fromentin JM (2001) Long-term fluctuations in the Eastern Atlantic and Mediterranean bluefin tune population. ICES J Mar Sci 58:1299-1317

Ripley BD (1976) The second-order analysis of stationnary point processes. J Appl Probab 13:255-266

Ripley BD (1977) Modelling spatial patterns. J R Stat Soc 39: $172-212$

Santos AM (1994) Satellite oceanography applications to the swordfish fishery off Portugal's continental west coast. MSc thesis, University of Lisbon

Shaw AGP, Vennell R (2000) A front-following algorithm for AVHRR SST imagery. Remote Sens Environ 72:317-327

Simpson JJ (1990) On the accurate detection and enchancement of oceanic features observed in satellite data. Remote Sens Environ 33:17-33

Sokal RR, Rohlf FJ (1969) Biometry. The principles and practice of statistics in biological research. WH Freeman \& Co., San Francisco

Steele JH (1989) The ocean 'landscape'. Landsc Ecol 3:185-192

Stoyan D, Stoyan H (1994) Fractals, random shapes and point fields. Wiley, Chichester

Ullman DS, Cornillon P (1999) Satellite-derived sea surface temperature fronts on the continental shelf off the northeast U.S. coast. J Geophys Res 104:23459-23478

Submitted: March 11, 2003; Accepted: November 18, 2003 Proofs received from author(s): March 8, 2004 